\section{Synovial Biopsy Findings in Arthritis Associated with Hepatitis C Virus Infection}

\section{To the Editor:}

The worldwide prevalence of arthritis presumed to be due to hepatitis $\mathrm{C}$ virus (HCV) infection has been reported between 2.4 million and 45.9 million people ${ }^{1,2}$. Histopathological changes in $\mathrm{HCV}$-associated synovitis have not been examined. We have performed a histological and immunohistochemical analysis of synovial biopsies from the knee joints of 2 patients with $\mathrm{HCV}$ infection and arthritis.

Laboratory values are summarized in Table 1 . Patient 1 was a 56-yearold African American man with joint pain involving hands, wrists, elbows, shoulders, knees, and ankles of 4 months' duration. There was no history of sexually transmitted diseases or gastroenteritis in the preceding months. Physical examination revealed warmth, swelling, and tenderness over the elbows, wrists, metacarpals, proximal interphalangeal joints, knees, ankles, and metatarsal bones. A closed-needle synovial biopsy was performed on 1 knee joint. At 3 years' followup, the patient is maintained on low-dose prednisone and continues to have arthralgias but no overt joint swelling.

Patient 2 was a 42-year-old white man with a painful right knee effusion of 1 month's duration. He denied prior trauma or illness, but reported sweats and chills. There was no recent history of sexually transmitted diseases and no gastroenteritis in the months prior. A closed-needle synovial biopsy was performed on the affected knee joint. Symptoms resolved after an intraarticular injection of triamcinolone hexacetonide and subsequent treatment with nonsteroidal antiinflammatory drugs. Two years later the arthritis has not recurred.

Synovial tissue sections from both patients were stained with $\mathrm{H} \& \mathrm{E}$ or immunostained for CD15 (neutrophilic granulocytes), CD3, CD20, CD38, $\mathrm{CD} 68, \mathrm{Ki}-67$, and von Willebrand factor $(\mathrm{vWF})^{3,4}$. A previously validated synovitis score ${ }^{5}$ was modified in that the score of each specimen represents the average of 5-10 microscopic fields (200× magnification). Results were compared to results from synovial membranes from osteoarthritis $(\mathrm{OA} ; \mathrm{n}=$ 26) and rheumatoid arthritis $(\mathrm{RA} ; \mathrm{n}=28)^{3,4,6,7}$. Vascular density was also compared to normal synovium ( $\mathrm{n}=15 ; ;^{7}$ and unpublished data). Expression differences were assessed with receiver-operating characteristic (ROC) curve analysis (SPSS 14.0 software).

Focal lining hyperplasia occurred in both specimens (Figure 1), but

Table 1. Laboratory values.

\begin{tabular}{lcc}
\hline Measurement & Patient 1 & Patient 2 \\
\hline Leukocytes $/ \mathrm{mm}^{3}\left(\times 10^{3}\right)$ & 4.4 & 6.4 \\
Hemoglobin, $\mathrm{g} / \mathrm{dl}$ & 10.7 & 12.1 \\
Platelets $/ \mathrm{mm}^{3}\left(\times 10^{3}\right)$ & 303 & 360 \\
ESR, $\mathrm{mm} / \mathrm{h}$ & 81 & 80 \\
$\mathrm{CRP}, \mathrm{mg} / \mathrm{l}$, normal $<5$ & $\mathrm{ND}$ & 10 \\
$\mathrm{RF}, \mathrm{IU} / \mathrm{ml}$, normal $<20$ & 25.8 & $<20$ \\
Anti-CCP & $\mathrm{ND}$ & Negative \\
$\mathrm{C} 3$ and C4 & Normal & ND \\
Cryoglobulins & Negative & ND \\
Chlamydia PCR, synovium & Negative & Negative \\
HIV, HBV serology & Negative & Negative \\
Viral load, copies $/ \mathrm{ml}$ & $>1 \times 10^{6 *}$ & $1.5 \times 10^{5 \dagger}$ \\
& $5.3 \times 10^{6 * *}$ & $6.3 \times 10^{5 \dagger \dagger}$ \\
HCV genotype & $1 \mathrm{~A}$ & $1 \mathrm{~B}$ \\
SF cell count, leukocytes $/ \mathrm{mm}^{3}$ & 6050 & 50,715 \\
\end{tabular}

* Two years before biopsy; $* * 3$ years after biopsy; ${ }^{\dagger} 1$ year before biopsy; $\dagger 2$ years after biopsy. $\mathrm{C} 3$ and C4: complement components 3 and 4; CCP: cyclic citrullinated peptide; CRP: C-reactive protein; ESR: erythrocyte sedimentation rate; HBV: hepatitis B virus; HIV: human immunodeficiency virus; ND: not determined; RF: rheumatoid factor; SF: synovial fluid; PCR: polymerase chain reaction; $\mathrm{HCV}$ : hepatitis $\mathrm{C}$ virus. also areas of normal or only minimally thickened lining. Fibrin deposits on the lining were seen in specimen 2 (Figure 1D). Subintimal adipose tissue was preserved in both specimens, and there was no fibrosis or necrosis. Small subintimal blood vessels were numerous in both specimens, but there were no degenerative vascular changes. Both specimens contained perivascular mononuclear infiltrates and at least 1 villus with more dramatic lining hyperplasia and denser mononuclear cell infiltration. The synovitis scores corresponded to mild (specimen 1) and moderate synovitis (specimen 2; Figure 2A). The mean lining thicknesses were much closer to $\mathrm{OA}$ than to RA (Figure 2B). Immunostains for vWF revealed that vascular densities of both $\mathrm{HCV}$ specimens were nearly identical to the mean measured in RA (Figure 2C) and 90\% higher than in normal synovium ${ }^{3,7}$. The proliferation-associated antigen Ki-67 was only detected in the subintima, at densities intermediate between OA and RA (Figure 2D).

CD68+ cells were detected widely in the lining, although expression was patchy at times. The density of CD68+ lining surface cells was similar to OA (Figure 2E). Inflammatory cell densities tended to be higher in specimen 2, whose values were closer to RA (Figure 2). CD68+ macrophages were the most common subintimal inflammatory cell type in both specimens. The subintimal CD68+ cell density from specimen 2 approached the mean value for RA, while the value from patient 1 was closer to OA (Figure 2F). CD3+ cells were the second most common (Figure 2G) and occurred in both perivascular and diffuse patterns. CD8+ cells were detected in both specimens in the CD3+ areas. Small foci of CD20+ and CD38+ cells occurred in both specimens, although these markers were less common than CD3 or CD68 (Figure 2H and 2I). Particularly, $\mathrm{CD} 38+$ cell densities were much lower in $\mathrm{HCV}$ than in RA. In contrast, densities of CD15+ cells were higher than (specimen 2) or similar to (specimen 1) the mean RA values (Figure 2J). Indeed, ROC analysis showed that the combination of $>25 \mathrm{CD} 15+$ cells $/ \mathrm{mm}^{2}$ and $<82 \mathrm{CD} 38+$ cells $/ \mathrm{mm}^{2}$ differentiated the $2 \mathrm{HCV}$ specimens from the RA specimens with a sensitivity and specificity of $100 \%$.

Mechanisms of arthritis in patients with HCV infection have not been clear. Attempts to detect $\mathrm{HCV}$ in the synovial fluid of patients with $\mathrm{HCV}$ infection and arthritis have mostly yielded negative results ${ }^{8}$. Therefore, we cannot prove that the synovitis is due to HCV infection of the synovial membrane. There was no evidence of other infections that might have caused a reactive arthritis. Patient 1 had a positive rheumatoid factor (RF), but RF and cyclic citrullinated peptide antibodies (which were not tested in this patient) do not discriminate well between RA and arthritis associated with $\mathrm{HCV}$ infection ${ }^{9,10}$. These 2 patients do represent the 2 types of hepatitis $\mathrm{C}$ arthritis described in the literature: a symmetrical RA-mimicking disease (case 1) and a monoarthritis (case 2), neither progressed to erosive disease ${ }^{1,2}$. At the same time, their synovial biopsies exhibited common histopathological features, suggesting that they may share pathogenetic mechanisms.

The severity of the synovitis in both specimens was milder than in active chronic RA; but the presence of at least 1 more intensely inflamed villus in each specimen suggests that $\mathrm{HCV}$-associated synovitis can be more severe. Thus, examination of additional specimens might reveal cases of higher-grade synovitis. Increased synovial vascularization has been described in chronic arthropathies ${ }^{4,7,11-13}$. Vascular density was nearly twice as high in the HCV specimens as in normal synovium (Figure 2C), possibly adding $\mathrm{HCV}$-associated arthritis to the arthropathies characterized by increased angiogenesis.

In summary, histopathological features of these 2 specimens of $\mathrm{HCV}$-associated arthritis included elevated CD15+ expression, a relative underrepresentation of humoral immunity in mononuclear infiltrates, and mild synovial lining hyperplasia but marked angiogenesis. These preliminary findings suggest the need for further study of whether HCV arthritis has consistent histopathological features.

ALEXIS OGDIE, MD, Fellow in Rheumatology, Department of Internal Medicine, University of Pennsylvania School of Medicine, Philadelphia, Pennsylvania; H. RALPH SCHUMACHER Jr, MD, Professor; LIE DAI, 

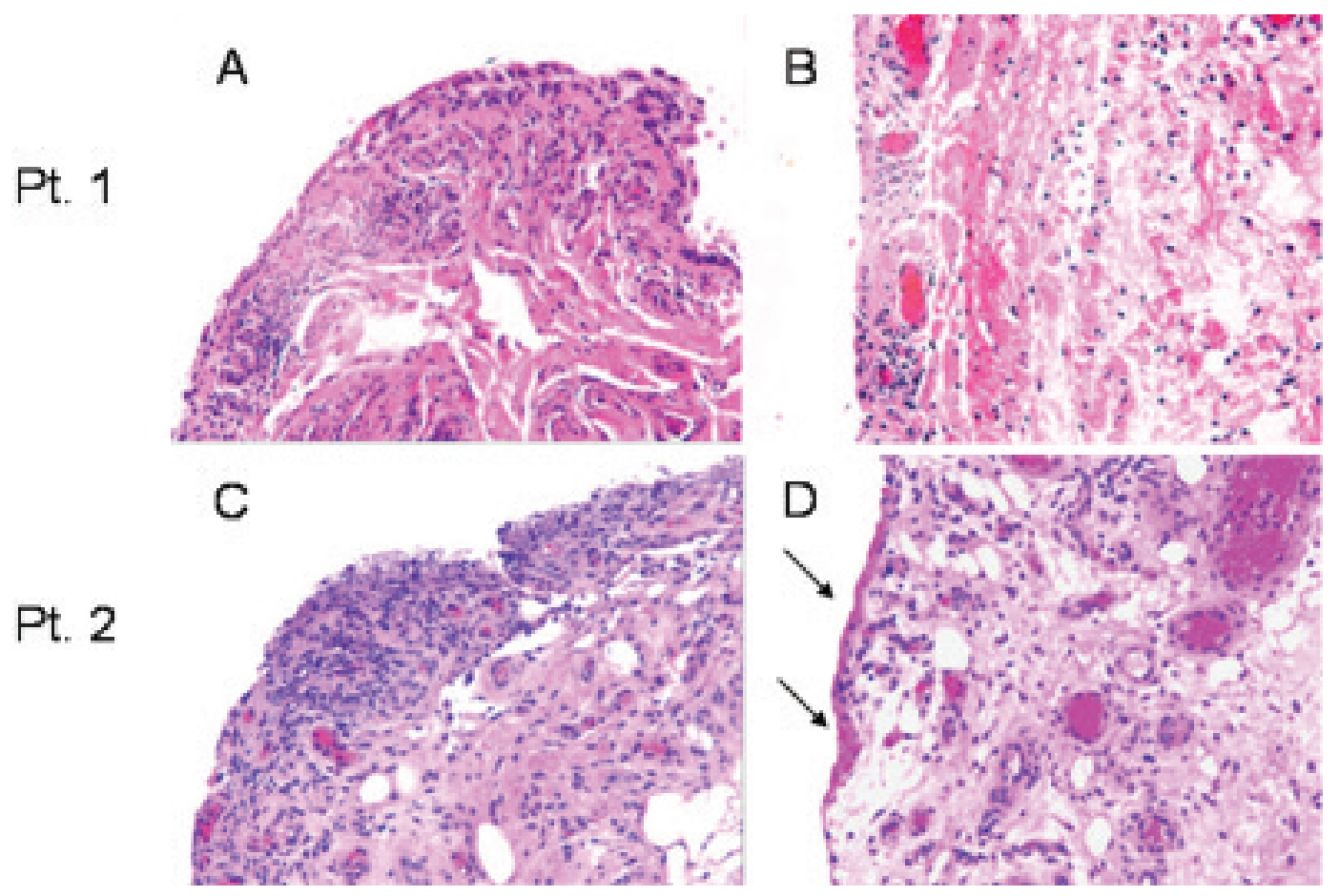

Figure 1. Evaluation of histologic alterations and vascular density. H\&E stains demonstrating selected histological abnormalities (original magnification, 100×). Tissues were obtained by closed-needle biopsy from clinically inflamed knee joints. A. and C. Maximally inflamed tissue areas demonstrating denser inflammatory infiltrates and intimal hyperplasia, particularly in specimen 2 (panel C). B. and D. More typical, mildly inflamed areas featuring only mild or no intimal hyperplasia, and less dense, perivascular inflammatory infiltration. Arrows indicate fibrin deposits on the intima of specimen 2.

MD, Professor, Division of Rheumatology, Philadelphia VA Medical Center; Second Affiliated Hospital, Sun Yat-sen University, Guangzhou, China; LAN X. CHEN, MD, Adjunct Assistant Professor, Division of Rheumatology, University of Pennsylvania School of Medicine and Division of Rheumatology, Philadelphia VA Medical Center; EUGENE EINHORN, MD, Pathologist, Department of Pathology, Philadelphia VA Medical Center; FRANK PESSLER, MD, PhD, Assistant Professor, University Children's Hospital, Technical University Dresden, Germany; Helmholtz Centre for Infection Research, Braunschweig, Germany. Address correspondence to Dr. F. Pessler. E-mail:

frank.pessler@helmholtz-hzi.de

Dr. Pessler was supported by National Institutes of Health Training Grants T32-AR 007442 and T32-CA 09140.

\section{REFERENCES}

1. Olivieri I, Palazzi C, Padula A. Hepatitis $\mathrm{C}$ virus and arthritis. Rheum Dis Clin North Amer 2003;29:111-22.

2. Rosner I, Rozenbaum M, Toubi E, Kessel A, Naschitz JE, Zuckerman E. The case for hepatitis C arthritis. Semin Arthr Rheum 2004;33:375-87.

3. Diaz-Torne C, Schumacher HR, Yu X, Gomez-Vaquero C, Dai L, Chen LX, et al. Absence of histologic evidence of synovitis in patients with Gulf War veterans' illness with joint pain. Arthritis Rheum 2007;57:1316-23.

4. Pessler F, Dai L, Diaz-Torne C, Gomez-Vaquero C, Paessler ME, Zheng DH, et al. The synovitis of "non-inflammatory" orthopaedic arthropathies: a quantitative histological and immunohistochemical analysis. Ann Rheum Dis 2008;67:1184-7.

5. Krenn V, Morawietz L, Burmester GR, Kinne RW, Mueller-Ladner
U, Muller B, et al. Synovitis score: discrimination between chronic low-grade and high-grade synovitis. Histopathology 2006; 49:358-64.

6. Pessler F, Ogdie A, Diaz-Torne C, Dai L, Yu X, Einhorn E, et al. Subintimal Ki-67 as a synovial tissue biomarker for inflammatory arthropathies. Ann Rheum Dis 2008;67:162-7.

7. Pessler F, Chen LX, Dai L, Gomez-Vaquero C, Diaz-Torne C, Paessler ME, et al. A histomorphometric analysis of synovial biopsies from individuals with Gulf War Veterans' Illness and joint pain compared to normal and osteoarthritis synovium. Clin Rheumatol 2008;27:1127-34.

8. Cimmino M, Picciotto A, Sinelli N, Brizzolara R, Accardo S. Has hepatitis $\mathrm{C}$ virus a specific tropism for the synovial membrane? $\mathrm{Br}$ J Rheumatol 1997;36:505-6.

9. Orge E, Cefle A, Yazici A, Guerel-Polat N, Hulagu S. The positivity of rheumatoid factor and anti-cyclic citrullinated peptide antibody in nonarthritic patients with chronic hepatitis $\mathrm{C}$ infection. Rheumatol Int 2010;30:485-8.

10. Bassyouni I, Ezzat Y, Hamdy S, Talaat R. Clinical significance of anti-cyclic citrullinated peptide antibodies in Egyptian patients with chronic hepatitis $\mathrm{C}$ virus genotype IV infection. Clin Chem Lab Med 2009;47:842-7.

11. Maruotti N, Cantatore FP, Crivellato E, Vacca A, Ribatti D Angiogenesis in rheumatoid arthritis. Histol Histopathol 2006;21:557-66.

12. Pessler F, Dai L, Diaz-Torne C, Ogdie A, Gomez-Vaquero C, Paessler ME, et al. Increased angiogenesis and cellular proliferation as hallmarks of the synovium in chronic septic arthritis. Arthritis Rheum 2008;59:1137-46. 
A
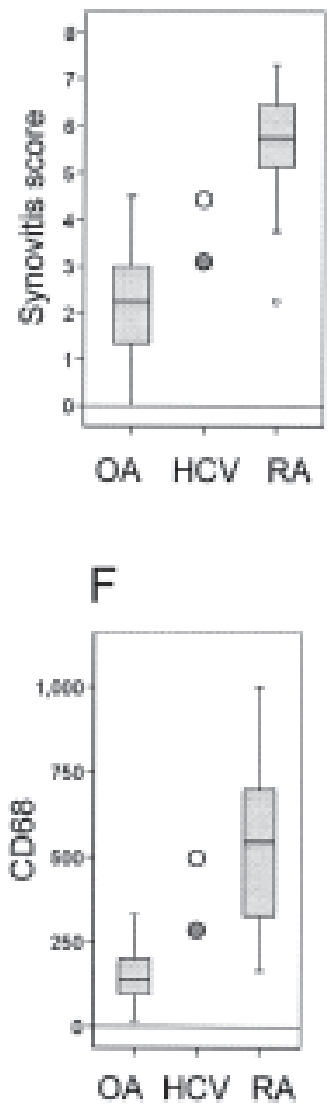

B

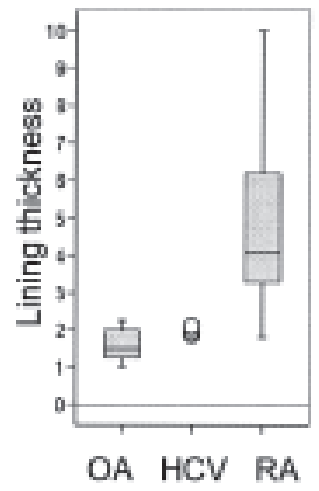

G

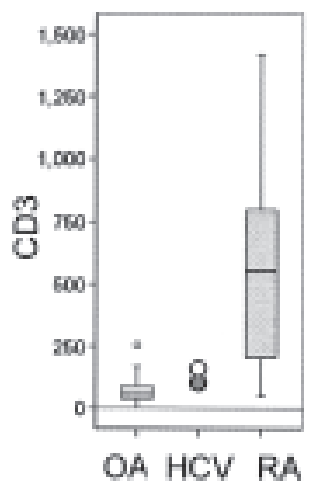

C

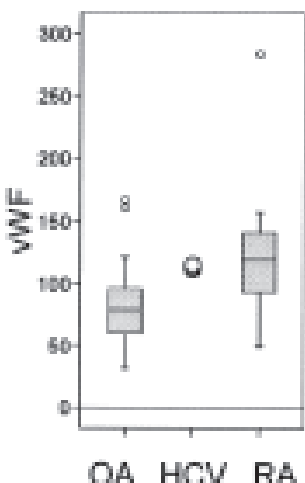

$\mathrm{H}$

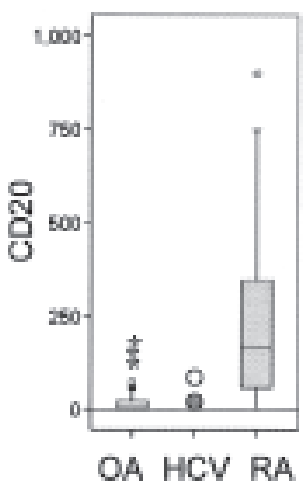

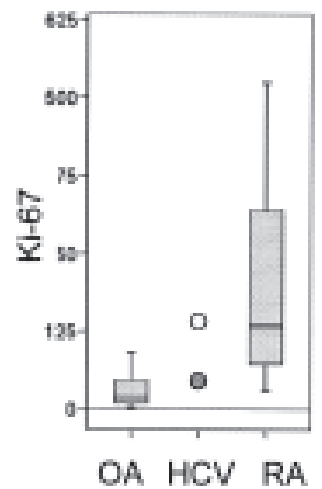

D

OA HCV RA

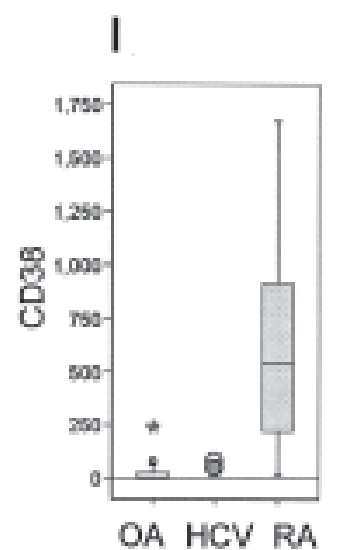

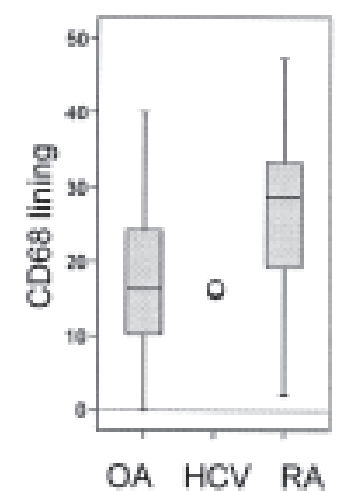

$\mathrm{E}$

OA HCV RA

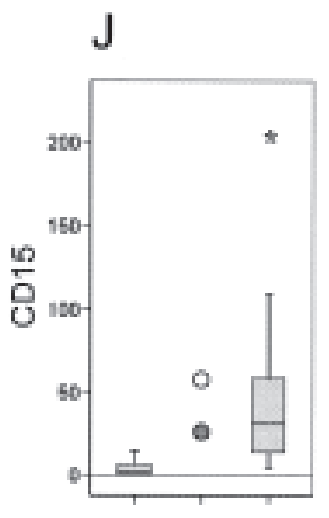

OA HCV RA

\section{$\bigcirc$ HCV Patient 1 O HCV Patient 2}

Figure 2. Results of quantitative evaluations. Box plots comparing histological and immunohistochemical markers in synovial membranes from individuals with osteoarthritis $(n=26)$, hepatitis $\mathrm{C}$ virus $(\mathrm{HCV})$ infection with arthritis $(\mathrm{n}=2)$, and rheumatoid arthritis $(\mathrm{n}=28)$. Horizontal line, median; lower edge of box, 25th percentile; upper edge of box, 75th percentile; upper and lower whiskers, maximal and minimal values; $*$ and $\bigcirc$, outliers possessing values greater than $3 \times(*)$ or $1.5 \times(\bigcirc)$ the height of the box above the 75 th percentile line. A. Synovitis score according to Krenn, et al ${ }^{14}$. Three components (lining hyperplasia, inflammatory infiltration, stromal density) are assigned values between 0 and 3, yielding a maximum score of 9 . B. Lining thickness (cell layers, average of 5-15 fields). C-J. Immunohistochemical markers. C. Vascular density (vessels $/ \mathrm{mm}^{2}$ ), as determined in sections immunostained for vWF. Vascular density of normal synovium, obtained by needle biopsy, corresponds to $58.9 \pm 3.0 \mathrm{SEM}$ vessels $/ \mathrm{mm}^{2} 7$ (and unpublished data), i.e., $48 \%$ and $49 \%$ lower than HCV specimens 1 and 2, respectively. D. Ki-67+ proliferating cells (positive staining cells $/ \mathrm{mm}^{2}$ ). E. CD68+ cells in the surface layer of the intima (positive staining cells/400× field). F-J. CD68+, CD3+, CD20+, CD38+, and CD15+ cells in the superficial subintima to a depth of one 400× microscopic field, i.e., $0.454 \mathrm{~mm}$ (positive staining cells $/ \mathrm{mm}^{2}$ ).

13. Baeten D, Demetter P, Cuvelier C, Van Den Bosch F, Kruithof E, Van Damme N, et al. Comparative study of the synovial histology in rheumatoid arthritis, spondyloarthropathy, and osteoarthritis: influence of disease duration and activity. Ann Rheum Dis 2000;59:945-53.
14.Krenn V, Morawietz L, Häupl T, Neidel J, Petersen I, König A. Grading of chronic synovitis - a histopathological grading system for molecular and diagnostic pathology. Pathol Res Pract 2002;198:317-25.

J Rheumatol 2010;37;6; doi:10.3899/jrheum.091309 